\title{
Causes And Prevention of Haze
}

\author{
Zhao Zhang and Jing He
}

\author{
North China Electric Power University, No.2, Beinong Road, Zhuxinzhuang, Changping District, B \\ eijing 102206, China \\ Email:530891104@qq.com \\ jij0716@qq.com
}

Keywords : Haze; Causes; Prevention; PM 2.5; Environmental

\begin{abstract}
Historical data shows that over the past 50 years China fog and haze overall in the increasing trend, and the persistent haze increases significantly. From the spatial distribution, the number of haze days shows a increasing trend in east and a decreasing one in west. Among them, the fastest growing region is the Pearl River Delta and Yangtze River Delta. From this spring, mist weather gradual emerges in the eastern part of China. As time past by, the scope of mist, fog and haze gradually increased, especially in Beijing, Tianjin and other places, where the several days' haze severely affects the quality of life of citizens. The composition of haze is very complex, and it has a very serious impact on humans and the environment. In this regard, I decided to study the cause and component of haze and search a way to prevent it, in order to establish a model to solve such problems .

The composition of haze is very complex, including hundreds of atmospheric chemistry particulate matter. Such as mineral particles, sea salt, sulfate, nitrate, organic aerosol particles, fuel and car exhaust, etc, which have a very serious bad impact on human health and the environment. So, what are the causes of haze ? What's the impact on the environment and human health? How to prevent? How the Government and relevant environmental authorities respond? We nitrogen dioxide generated by burning fossil fuels.
\end{abstract}

\section{Causes of haze}

Because of the weak cold air forces in the eastern region; less wind in North China Plain and the Yangtze River plains; stabilizing atmospheric structure, some regions are influenced by precipitation and evaporation of ground water, making the growing humidity of the air near the ground, while rarely fall rain. In this stable weather situation, pollutants in the air is not easily spread out in the horizontal and vertical directions, so that the contaminants accumulate in the atmosphere shallow, causing the worse contamination condition. These are natural factors of persistent fog and haze, the causes from human aspects is mainly the huge load of atmospheric pollutants. Academy of Social Sciences released "Green Paper on Climate Change: Addressing Climate Change report (2013)," pointed out most important reason is that the increasing fossil energy consumption results the social atmosphere emissions. In 2010, total emissions of sulfur dioxide, nitrogen oxides are more than 22 million tons, ranking first in the world. Industrial smoke dust emits 14,461,000 tons, far beyond the carrying capacity of the environment. In the world's 70 million tons of coal combustion in 2012, China burned 3.6 billion tons, accounting for $51 \%$, the emissions of exhaust gases can be imagined. And in most parts of the northern coal-fired capacity increased significantly in winter for heating, leading to a sharp increase in emissions of air pollutants. In the dual influence of atmospheric circulation and atmospheric chemistry, air pollution interact between cities is significantly, pollution transmission between adjacent urban is very prominent, Beijing, for example, produces about 30-40\% of PM2.5 gas and $20 \%-30 \%$ from the atmospheric photochemical conversion, $30-40 \%$ from the regional transport. The vehicle exhaust pollution can not be ignored, in addition, emissions of air pollutants also includes living (cooking, hot water), as well as ground dust. 


\section{The impact of haze}

Haze has significant adverse effects on road, rail, aviation, shipping, power supply system and the growth of crops. Fog, haze will cause air quality decreases and impacts environment. PM2.5 is directly harmful to human health. PM2.5 refers to the micron particles whose diameter is less than or equal to 2.5 in atmosphere, which is also known as inhalable particulate matter. Inhaled directly into the bronchia, disturbing pulmonary gas exchange, triggering asthma, bronchitis, cardiovascular disease and other diseases. And when foggy, the air pollutants is not easy diffuse in the city, resulting air with bacteria and viruses, which can easily lead to the infectious diseases and a variety of diseases. The moisture in the fog increased toxicity of sulfur dioxide, carbon monoxide, nitrogen oxides and other substances, threatening human health. Especially in case of fog in winter, air pollution may form soot or black smoke and other smog, becoming a serious threat to human life and health.

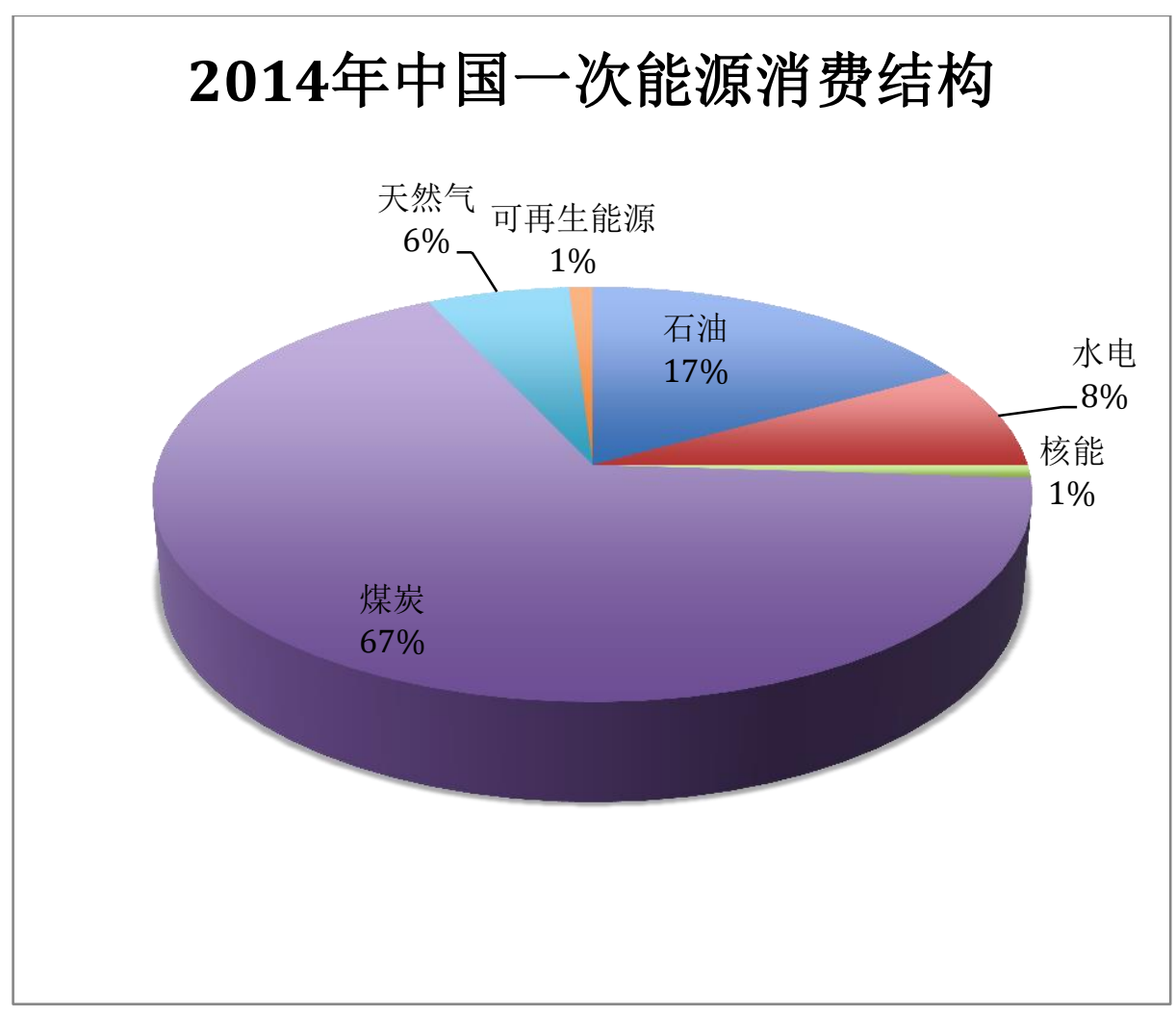

\section{Haze Prevention}

Governance of haze is a comprehensive, systematic project. PM2.5 and other particles are the main air pollution materials and are good condensation nuclei, too. The moisture in the atmosphere with the function of absorption, binding and fixing 'particles'. Therefore, transporting artificial "water" into the air is an effective way to improve regional climate, purify the atmosphere, affect the weather situation, and control air pollution in the region.

Intervening manually by the means of scientific and technology, making air into a cloud and causing rain, precipitation purify the air. This mechanism can largely reduce the number of total suspended particles in the air, reducing the fog and haze, achieving the purpose of pollution governance.

For the government, strengthening environmental protection legislation and improving the legal system is the fundamental way to solve the air pollution. The "Environmental Protection Law" and "Air Pollution Prevention Law" and other relevant environmental laws should be improved. Popularizing new energy and raising awareness of environmental to reduce the emission of pollutants from the source. 
Studying from the relationship between the energy consumption of the industrial structure, the total amount of China's energy consumption in 2011 was 34.8 million tons of coal, of which $70 \%$ is consumed by the industrial sector. And emitting carbon dioxide 6.19 billion tons. The energy metallurgy, building materials, power generation, petroleum refining, chemicals, heavy equipment manufacturing and other six industries consume $79 \%$ energy of total industrial energy consumption. Industrial emission is the main reason of haze formation. Therefore, the state must strengthen supervision of the industrial sector, under the premise of situation that the efficient and rapid economic development will not be affected, minimizing the use of fossil fuels, or increase the processing and handling of fuel gas , reducing fossil fuel proportion in energy consumption.

From the industrial layout study, China's heavy and chemical industries are mainly concentrated in the north, northeast and northwest. The proportion of energy consumption in north China's steel industry is too high. Only the crude steel production in Hebei province account $1 / 6$ of the country's capacity, and many of them are small enterprises with high energy consumption. Therefore, we must optimize the layout of the steel industry, gradually closing down those low efficiency and high polluting ones. Improving the efficiency of fuel use, thereby reducing the burning of fossil fuels and emissions. Reducing the amount of nitrogen oxides in the air, in order to mitigate the effects of haze on the city and the human body.

In addition, to solve the problem of vehicle emissions, the mandatory installation of gas purification device can be a good way. But dealing with the gas is only a palliative, increasing the use of public transport and clean energy vehicles is fundamental.

\section{The revelation of frequent fog and haze to us}

National environmental problems are Mother Nature in a warning to us. If we want a healthy life, we must be kind to the environment; if we want a harmonious society, we must be harmonious with natural. Environmental issues are people issues in the final, and the problem of people always comes down to the legal and education, environmental protection needs national attention and public participation.

\section{References}

[1] Chengdu Institute of Meteorology. Meteorology [M]. Beijing: Agricultural Press, 1980.

[2] China Meteorological Administration. Meteorological observation specification [M]. Beijing: China Meteorological Press, 2003.

[3]Why haze days increased [N]. People's Daily, 2011-12-19

[4]Zhang Tingting Analysis of the Harzad of PM2.5 and Measures [J]. China Environmental Management, 2012, 3: 19-23.

[5] Huang Zhongtao,Geng Jianming Industrial Catalysis. Second Edition .2006 August 2nd Edition

[6] Pan Xuemei Hebei southern regions and sources of haze pollution. [D] Shijiazhuang: Hebei University (Master) project, 2012

[7] Duan Zaiming Analysis of Causes of fog and haze of Shanxi [J]. Taiyuan University of Technology, 2011,42

[8]W. G. Tucker. An overview of PM sources and control strategies. Fuel Processing Technology, 20 00, 65-66: 379-392.

[9] Wang Runqing. Meteorology definition of fog and haze and preventive measures [J]. Modern Agricultural Science and Technology, 2012 (7): 44 
[10] Wuqing Mei, Zhang Shengjun. Influence of Pollution Factors of Foggy Weather [J]. Meteorology and Environmental Science, 2010,33 (1): 12-16 